\title{
Glutathione S-transferase A1 mediates nicotine-induced lung cancer cell metastasis by promoting epithelial-mesenchymal transition
}

\author{
WEI WANG ${ }^{1,2^{*}}$, FEIYU LIU $^{3 *}$, CHAOYANG WANG $^{1}$, CHENGDE WANG $^{1}$, YIJUN TANG $^{1}$ and ZHONGMIN JIANG $^{2}$ \\ ${ }^{1}$ Department of Thoracic Surgery, Yantai Yuhuangding Hospital, Qingdao University, Yantai, Shandong 264000; \\ ${ }^{2}$ Department of Thoracic Surgery, Shandong Provincial Qianfoshan Hospital, Shandong University, Jinan, Shandong 250014; \\ ${ }^{3}$ Department of Pharmacy, Yantai Yuhuangding Hospital, Qingdao University, Yantai, Shandong 264000, P.R. China
}

Received May 4, 2016; Accepted March 31, 2017

DOI: $10.3892 /$ etm.2017.4663

\begin{abstract}
The present study aimed to investigate the effect of glutathione S-transferase A1 (GSTA1) on lung cancer cell viability, invasion and adhesion in the presence of nicotine in vitro. Furthermore, the effect of GSTA1 on the epithelial-mesenchymal transition (EMT), a process strongly associated with lung cancer metastasis, was examined. Human lung carcinoma A549 cells were treated with various concentrations of nicotine $(0.01,0.1,1$ and $10 \mu \mathrm{M})$ and levels of GSTA1 mRNA and protein were measured by reverse transcription-quantitative polymerase chain reaction and western blot analysis, respectively. To knock down GSTA1 expression, GSTA1-small interfering RNA was transfected into A549 cells. Cell viability, invasion and adhesion abilities were determined by MTT, Transwell-Matrigel invasion and cell adhesion assays, respectively. The expression of the epithelial cell markers E-cadherin and keratin, and the mesenchymal cell markers vimentin and N-cadherin in A549 cells were examined by western blot analysis. The current study indicated that the expression of GSTA1 was increased in A549 cells following nicotine treatment. GSTA1 suppression inhibited the viability, invasion and adhesion of lung cancer cells. In addition, the increase in lung cancer cell viability, invasion and adhesion by nicotine was suppressed following GSTA1 knockdown. Furthermore, GSTA1 affected the expression of EMT markers in nicotine-treated or untreated lung cancer cells. Thus the present study demonstrates that GSTA1 promotes lung cancer cell invasion and adhesion and mediates
\end{abstract}

Correspondence to: Dr Zhongmin Jiang, Department of Thoracic Surgery, Shandong Provincial Qianfoshan Hospital, Shandong University, 16766 Jingshi Road, Jinan, Shandong 250014, P.R. China E-mail: qy_jzm@163.com

${ }^{*}$ Contributed equally

Key words: glutathione S-transferase A1, lung cancer, metastasis, epithelial-mesenchymal transition, nicotine the effect of nicotine on lung cancer cell metastasis in vitro. Furthermore, the results demonstrated that GSTA1 exerts its effect on lung cancer cell metastasis by promoting the EMT.

\section{Introduction}

Globally, lung cancer is the leading cause of cancer-associated mortality in men and the second leading cause of cancer-associated mortality in women (1). Recurrence and metastasis are the biggest obstacles to effective lung cancer treatment. Although treatments for lung cancer have improved over the past few decades, the 5-year survival rate is only $\sim 16 \%$ (2). Thus, it is important to identify biomarkers associated with lung cancer metastasis in order to improve the therapeutic strategies available.

Tumor metastasis is a complex process consisting of multiple biological steps (3) including increased motility, invasion into surrounding tissue, intravasation, entry and survival in the circulation, extravasation and eventual colonization of a distant site (4-6). The epithelial-mesenchymal transition (EMT) is a well-coordinated process that induces metastasis in epithelial cancer $(7,8)$. Glutathione S-transferase A 1 (GSTA1) is an isoform of GST primarily involved in the detoxification of electrophilic compounds by undergoing conjugation with glutathione $(9,10)$. Previous studies have demonstrated that the altered expression of GST genes increases the risk of prostate cancer and hepatocellular carcinoma (11-14). Recently, Pan et al (15) identified the potential of GSTA1 in the early diagnosis and treatment of lung cancer. It was determined that the expression of GSTA1 in lung cancer tissues and cells was higher than in healthy tissues and cells, and that GSTA1 suppression inhibits the proliferation of lung cancer cells. However, to the best of our knowledge, the potential role of GSTA1 in lung cancer metastasis has not yet been investigated.

It is estimated that $\sim 85 \%$ of total lung cancer cases occur in tobacco smokers (16). Nicotine is the major addictive component of tobacco smoke and many of the carcinogens in tobacco smoke are derivatives of nicotine (17). Numerous studies have demonstrated that nicotine promotes the growth and metastasis of lung tumors (18-20). 
In the present study, GSTA1-small interfering RNA was transfected into A549 cells to knock down GSTA1 expression, and the effect of GSTA1 on the viability, invasion and adhesion of lung cancer cells was investigated in the presence of nicotine in vitro. Furthermore, the effect of GSTA1 on EMT, a process strongly associated with lung cancer metastasis, was examined by western blot analysis.

\section{Materials and methods}

Cell culture and transfection. The A549 cell line was obtained from the American Type Culture Collection (Manassas, VA, USA) and cultured in Dulbecco's modified Eagle's medium (DMEM; Invitrogen; Thermo Fisher Scientific, Inc., Waltham, MA, USA) containing 10\% newborn calf serum (NBCS; Invitrogen; Thermo Fisher Scientific, Inc.). Cells were maintained at $37^{\circ} \mathrm{C}$ in a humidified atmosphere containing 5\% $\mathrm{CO}_{2}$. A549 cells were seeded $\left(1 \times 10^{5}\right)$ in DMEM and Nicotine (Sigma-Aldrich; Merck KGaA, Darmstadt, Germany) was used to treat A549 cells at the concentrations of $0.01,0.1,1$ and $10 \mu \mathrm{M}$ at $37^{\circ} \mathrm{C}$ for $24 \mathrm{~h}$. The concentration of nicotine was selected by assessing which nicotine concentration exhibited the maximum effect on GSTA1 expression for subsequent experiments. Cells were treated with nicotine for 6, 12, 24 and $48 \mathrm{~h}$ in the preliminary experiments, and $24 \mathrm{~h}$ was selected as the duration following treatment with $10 \mu \mathrm{M}$ nicotine, as together they had the maximum effect on GSTA1 expression for the subsequent experiments. GSTA1-small interfering RNA (siRNA) was synthesized by Sangon Biotech Co., Ltd. (Shanghai, China). A scramble siRNA (Sangon Biotech Co., Ltd.) was used as the control. A549 cells were transfected with siRNA $(1 \mu \mathrm{M})$ using Lipofectamine ${ }^{\circledR} 2000$ (Invitrogen; Thermo Fisher Scientific, Inc.) following the manufacturer's instructions. The cells used in this study were divided into four groups: PBS + Scr group (cells were transfected with scramble siRNA and treated with $1 \mu \mathrm{l}$ PBS), PBS + Si group (cells were transfected with GSTA1-siRNA and treated with $1 \mu 1$ PBS), Nicotine + Scr group (cells were transfected with scramble siRNA and treated with $10 \mu \mathrm{M}$ nicotine) and Nicotine $+\mathrm{Si}$ group (cells were transfected with GSTA1-siRNA and treated with $10 \mu \mathrm{M}$ nicotine). The PBS + Scr group was used as the control.

Reverse transcription-quantitative polymerase chain reaction (RT-qPCR). Total RNA was isolated from A549 cells using TRIzol reagent (Invitrogen; Thermo Fisher Scientific, Inc.). Total RNA (1 $\mu \mathrm{g})$ was converted into cDNA using a First Strand cDNA Synthesis kit (Fermentas; Thermo Fisher Scientific, Inc.) following the manufacturer's instructions. The following primers were used in the present study: GSTA1, forward, 5'-GGCTGCAGCTGGAGTAGAGT-3' and reverse 5'-GCAAGCTTGGCATCTTTTTC- 3 ' and $\beta$-actin, forward, 5'-AGAGCTACGAGCTGCCTGAC-3' and reverse 5'-AGCACTGTGTTGGCGTACAG-3'. qPCR was performed using a SYBR Green PCR kit (Applied Biosystems; Thermo Fisher Scientific, Inc.) in a 7300 Sequence Detection system (Applied Biosystems; Thermo Fisher Scientific, Inc.). The reaction was performed over 40 cycles at $95^{\circ} \mathrm{C}$ for $30 \mathrm{sec}$, $59^{\circ} \mathrm{C}$ for $30 \mathrm{sec}$ and $72^{\circ} \mathrm{C}$ for $30 \mathrm{sec}$. All reactions were performed in triplicate. Levels of GSTA1 mRNA were normalized to those of $\beta$-actin, as an internal control using the $2^{-\Delta \Delta C q}$ method (21).

Western blot analysis. Total protein was extracted using radioimmunoprecipitation assay lysis buffer (Beyotime Institute of Biotechnology, Shanghai, China) according to the manufacture's protocol. Briefly, the cells were incubated with the lysis buffer at room temperature for $5 \mathrm{~min}$. Then cell lysates were centrifuged at $13,000 \mathrm{x}$ g for $5 \mathrm{~min}$ at room temperature and supernatants were harvested. Equal amounts of total protein $(20 \mu \mathrm{g})$ were separated using $12 \%$ SDS-PAGE and subsequently transferred onto nitrocellulose membranes (EMD Millipore, Billerica, MA, USA). Following blocking with $3 \%$ bovine serum albumin (Sigma-Aldrich; Merck $\mathrm{KGaA}$ ) at $4^{\circ} \mathrm{C}$ overnight, membranes were incubated with keratin rabbit polyclonal antibody (1:400; cat. no. 41723; Signalway Antibody Inc., College Park, MD, USA), GSTA1 monoclonal antibody (1:500; cat. no. sc-100546), E-cadherin rabbit polyclonal antibody (1:500; cat. no. sc-7870), vimentin monoclonal antibody (1:800; cat. no. sc-373717), N-cadherin mouse monoclonal antibody (1:500; cat. no. sc-393933) and $\beta$-actin monoclonal antibody $(1: 1,000$; cat. no. sc-130301; all Santa Cruz Biotechnology, Inc., Dallas, TX, USA) at $4^{\circ} \mathrm{C}$ overnight. Membranes were subsequently incubated with horseradish peroxidase-labeled goat anti-mouse $(1: 2,000$; cat. no. sc-2005) or goat anti-rabbit antibodies (1:2,000; cat. no. sc-2004; both Santa Cruz Biotechnology, Inc.) at $37^{\circ} \mathrm{C}$ for $1 \mathrm{~h}$. Immunoreactive bands were detected using an enhanced chemiluminescence detection kit (Pierce; Thermo Fisher Scientific, Inc.). ImageJ version 1.37 software (National Institutes of Health, Bethesda, MD, USA) was used for quantification, and the experiments were independently performed three times.

MTT assay. An MTT assay was performed to determine cell viability. A549 cells were plated into 96-well plates at the density of $1 \times 10^{4} /$ well, and allowed to grow at $37^{\circ} \mathrm{C}$ for 24,48 , 72 and $96 \mathrm{~h}$. Subsequently, they were incubated with MTT solution $\left(1 \mathrm{mg} / \mathrm{ml}\right.$; Sigma-Aldrich; Merck KGaA) at $37^{\circ} \mathrm{C}$ for 4 h. Dimethyl sulfoxide (Sigma-Aldrich; Merck KGaA) was added to each well to solubilize the formazan product. Control cells were incubated with the dimethyl sulfoxide alone. The absorbance of each sample at $570 \mathrm{~nm}$ was measured using a microplate reader (Multiskan Ascent, Thermo Fisher Scientific, Inc.).

Cell invasion assay. The invasion of A549 cells was measured using a Transwell-Matrigel assay. Transwell inserts (Corning, Inc., Corning, NY, USA) were precoated with Matrigel matrix (BD Biosciences, Franklin Lakes, NJ, USA) at $37^{\circ} \mathrm{C}$ for $30 \mathrm{~min}$. Cells were trypsinized and plated into the upper chambers at a concentration of $3 \times 10^{4}$ cells $/ \mathrm{ml}$ in serum-free DMEM. Cell medium containing 10\% NBCS was added to the lower chambers. The chambers were incubated at $37^{\circ} \mathrm{C}$ overnight and a cotton swab was used to remove non-invasive cells. The invasive cells were then fixed in $95 \%$ ethanol at room temperature for $15 \mathrm{~min}$ followed by staining in hematoxylin for $10 \mathrm{~min}$. The invaded cells were observed under an inverted microscope (XDS-200D; Caikon Optical Instrument Co., Ltd, Shanghai, China) at a magnification of 
$\mathrm{x} 400$, and counted in 10 randomly selected fields in three independent experiments.

Cell adhesion assay. The 96-well plates were precoated with fibronectin (Sigma-Aldrich; Merck KGaA) and then blocked with $1 \%$ bovine serum albumin at $37^{\circ} \mathrm{C}$ for $2 \mathrm{~h}$. A total of $3 \times 10^{4}$ A549 cells in serum-free DMEM were seeded into each well and incubated at $37^{\circ} \mathrm{C}$ for $2 \mathrm{~h}$. Following washing with phosphate-buffered saline, cells were fixed in $4 \%$ paraformaldehyde (Shanghai Solarbio Bioscience \& Technology Co., Ltd., Shanghai, China) at room temperature for $30 \mathrm{~min}$. Subsequently, cells were stained with $0.5 \%$ crystal violet (Beyotime Institute of Biotechnology) followed by incubation with $2 \%$ SDS at room temperature for $1 \mathrm{~min}$. The absorbance at $570 \mathrm{~nm}$ was measured using a microplate reader.

Statistical analysis. All the data are presented as the mean \pm standard deviation. Statistical analysis was performed using SPSS 19.0 statistical software (SPSS, Inc., Chicago, IL, USA). One-way analysis of variance followed by the least significant difference test was used for comparison of multiple groups and $\mathrm{P}<0.05$ was considered to indicate a statistically significant difference.

\section{Results}

$m R N A$ and protein expression of GSTAl is induced by nicotine in A549 cells. A549 cells were treated with 0,0.01, $0.1,1$ or $10 \mu \mathrm{M}$ nicotine for $24 \mathrm{~h}$. Subsequently, levels of GSTA1 mRNA and protein were examined by RT-qPCR and western blot analysis, respectively. Results from RT-qPCR demonstrated that levels of GSTA1 mRNA were elevated in A549 cells following nicotine stimulation and the maximum level was reached at $10 \mu \mathrm{M}$. Compared with controls, levels of GSTA1 mRNA were significantly increased following treatment with $0.1(\mathrm{P}<0.05), 1(\mathrm{P}<0.01)$ and $10 \mu \mathrm{M}(\mathrm{P}<0.01)$ nicotine (Fig. 1A). Similar results were obtained following western blot analysis (Fig. 1B). We treated cells with nicotine for $6,12,24$ and $48 \mathrm{~h}$ in the preliminary experiments, and 6 and $12 \mathrm{~h}$ of incubation was demonstrated to exhibit no effect on GSTA1 expression. Following preliminary assessments, $10 \mu \mathrm{M}$ nicotine was selected for use in subsequent experiments, as the concentration of nicotine that exhibited the maximum effect on GSTA1 expression to treat cells, following $24 \mathrm{~h}$ of incubation, for the subsequent experiments.

GSTA1 suppression inhibits the nicotine-induced increased viability of A549 cells. To knock down GSTA1 expression, A549 cells were transfected with GSTA1-siRNA; scramble siRNA was used as a control. It was demonstrated by western blot analysis that levels of GSTA1 protein were significantly decreased in A549 cells following GSTA1-siRNA transfection $(\mathrm{P}<0.05)$. Treatment with nicotine significantly increased GSTA1 expression compared with controls $(\mathrm{P}<0.01)$, however, this increase in GSTA1 expression by nicotine was abrogated following transfection with GSTA1-siRNA ( $\mathrm{P}<0.01$; Fig. 2).

To investigate the role of GSTA1 on cell viability, A549 cells transfected with GSTA1-siRNA were treated with $10 \mu \mathrm{M}$ nicotine for $24 \mathrm{~h}$ and an MTT assay was performed. As
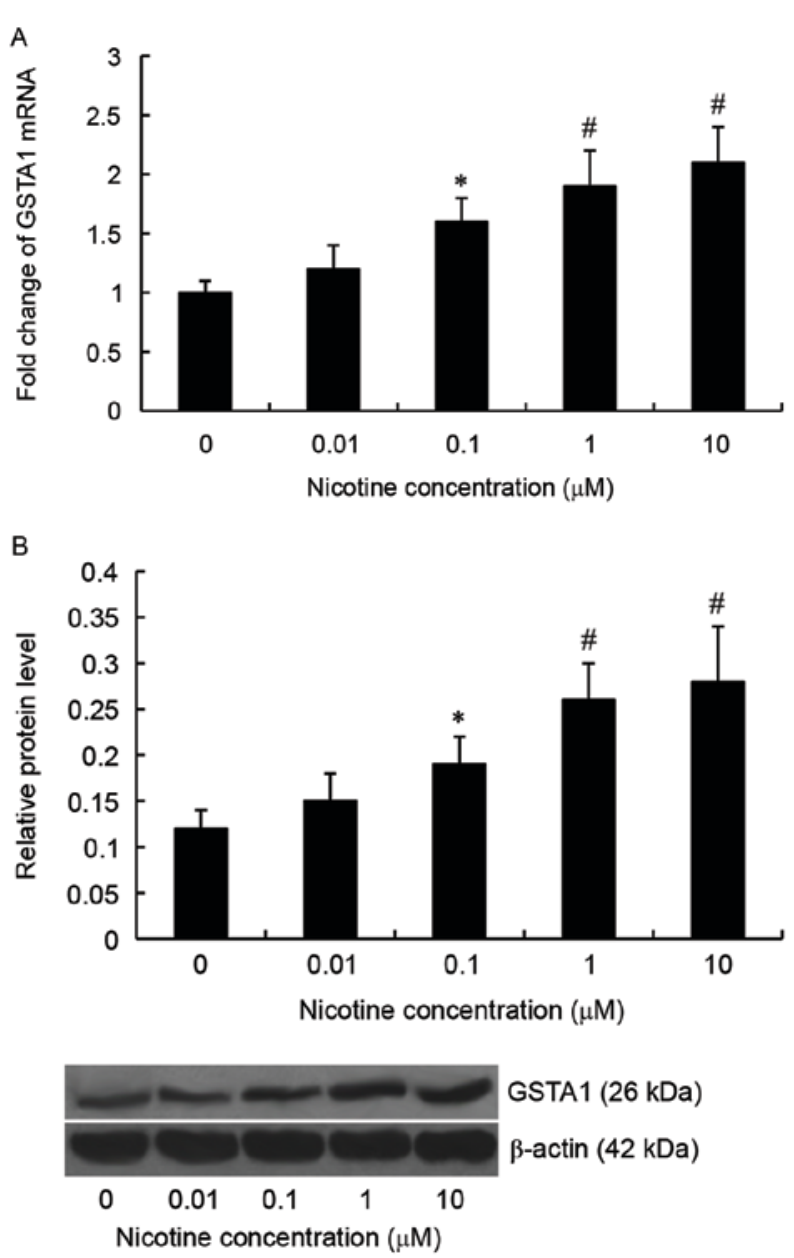

Figure 1. Levels of GSTA1 mRNA and protein in A549 cells following treatment with $0,0.01,0.1,1$ or $10 \mu \mathrm{M}$ nicotine. (A) Relative mRNA expression of GSTA1. (B) Relative protein expression of GSTA1. * $\mathrm{P}<0.05$ and ${ }^{\#} \mathrm{P}<0.01$ vs. $0 \mu \mathrm{M}$ nicotine. GSTA1, glutathione $\mathrm{S}$-transferase alpha 1.

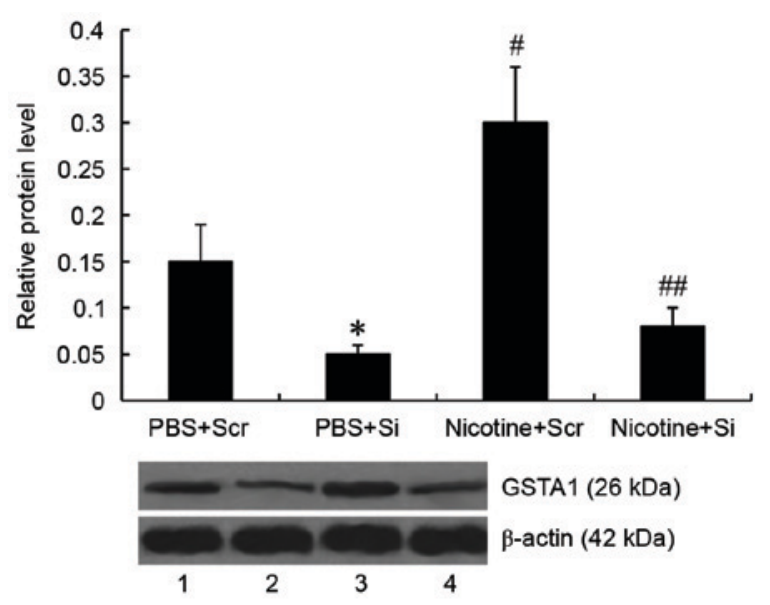

Figure 2. Expression of GSTA1 in A549 cells following treatment with nicotine and transfection with siRNA. ${ }^{*} \mathrm{P}<0.05$ and ${ }^{\#} \mathrm{P}<0.01$ vs. $\mathrm{PBS}+\mathrm{Scr}$; ${ }^{\# \#} \mathrm{P}<0.01$ vs. Nicotine + Scr. Lane $1, \mathrm{PBS}+\mathrm{Scr}$; lane $2, \mathrm{PBS}+\mathrm{Si}$; lane 3 Nicotine + Scr; lane 4, Nicotine + Si. GSTA1, glutathione S-transferase alpha 1; si, siRNA; siRNA, small interfering RNA; Scr, scramble RNA.

presented in Fig. 3, nicotine stimulation significantly increased the viability of A549 cells transfected with scramble siRNA 


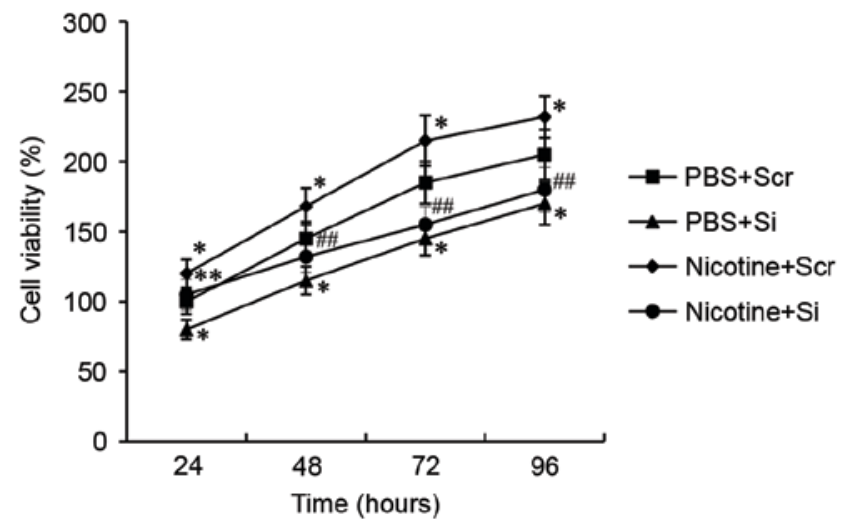

Figure 3. Viability of A549 cells following treatment with $10 \mu \mathrm{M}$ nicotine and transfection with siRNA. ${ }^{*} \mathrm{P}<0.05$ vs. PBS $+\mathrm{Scr} ;{ }^{* *} \mathrm{P}<0.05$ and ${ }^{\# \#} \mathrm{P}<0.01$ vs. Nicotine + Scr. GSTA1, glutathione S-transferase alpha 1; Si, siRNA; siRNA, small interfering RNA; Scr, scramble RNA.

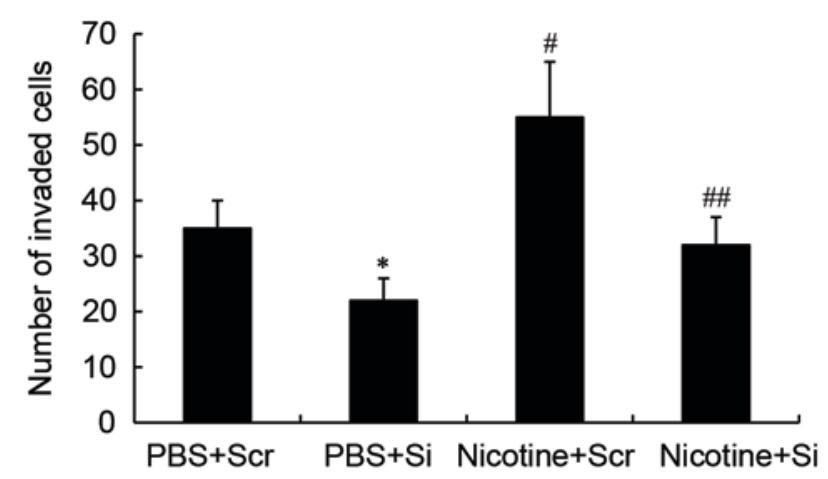

Figure 4. Invasion of A549 cells following treatment with $10 \mu \mathrm{M}$ nicotine and transfection with siRNA. ${ }^{*} \mathrm{P}<0.05$ and ${ }^{\#} \mathrm{P}<0.01$ vs. $\mathrm{PBS}+\mathrm{Scr} ;{ }^{\# \#} \mathrm{P}<0.01$ vs. Nicotine + Scr. GSTA1, glutathione S-transferase alpha 1; Si, siRNA; siRNA, small interfering RNA; Scr, scramble RNA.

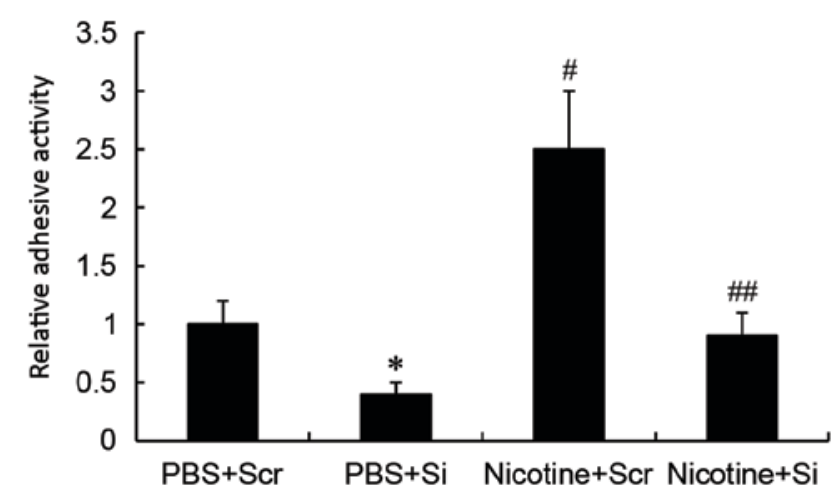

Figure 5. Adhesion of A549 cells following treatment with $10 \mu \mathrm{M}$ nicotine and transfection with siRNA. ${ }^{*} \mathrm{P}<0.05$ and ${ }^{\#} \mathrm{P}<0.01$ vs. $\mathrm{PBS}+\mathrm{Scr} ;{ }^{\# \#} \mathrm{P}<0.01$ vs. Nicotine + Scr. GSTA1, glutathione S-transferase alpha 1; Si, siRNA; siRNA, small interfering RNA; Scr, scramble.

compared with untreated A549 cells $(\mathrm{P}<0.05)$. However, viability was significantly reduced following transfection with GSTA1-siRNA in nicotine-treated cells compared with the nicotine-treated scramble-siRNA cells $(\mathrm{P}<0.01)$ and in untreated cells transfected with GSTA1-siRNA compared with untreated cells transfected with scramble siRNA $(\mathrm{P}<0.05)$.

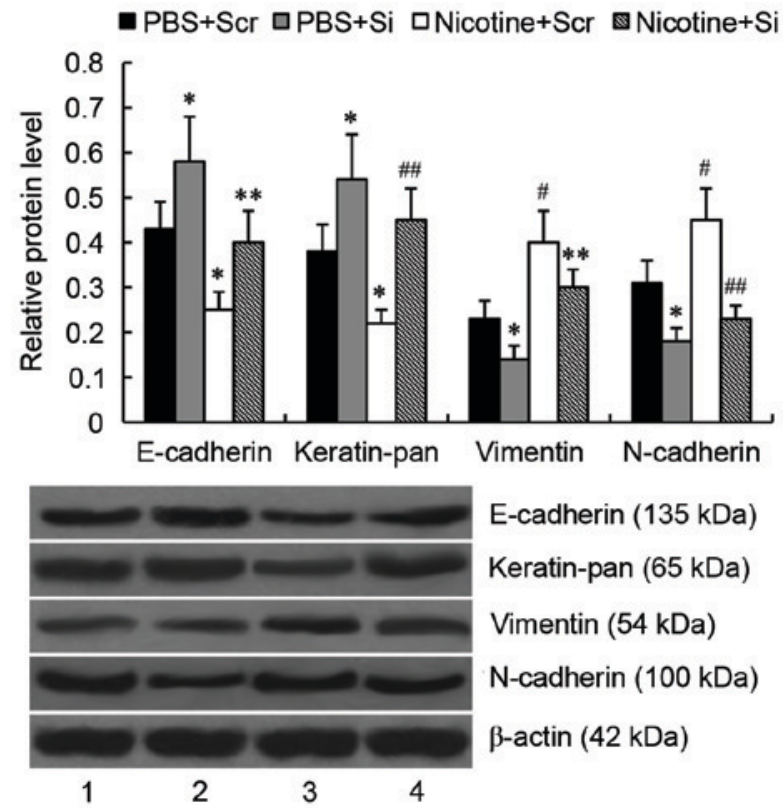

Figure 6. Levels of epithelial-mesenchymal transition markers in A549 cells following treatment with $10 \mu \mathrm{M}$ nicotine and transfection with siRNA. ${ }^{*} \mathrm{P}<0.05$ and ${ }^{\#} \mathrm{P}<0.01$ vs. $\mathrm{PBS}+\mathrm{Scr} ;{ }^{* *} \mathrm{P}<0.05$ and ${ }^{\# \#} \mathrm{P}<0.01$ vs. Nicotine + Scr. Lane 1, PBS + Scr; lane 2, PBS + Si; lane 3, Nicotine + Scr; lane 4, Nicotine + Si. GSTA1, glutathione S-transferase alpha 1; Si, siRNA; siRNA, small interfering RNA; Scr, scramble RNA.

GSTA1 suppression inhibits the nicotine-induced invasion abilities of A549 cells. A Transwell-migration assay was performed to determine whether GSTA1 affects cell invasion. In PBS-treated cells, GSTA1 knockdown significantly decreased the cell invasion ability $(\mathrm{P}<0.05)$ compared with cells transfected with scramble siRNA. The invasion ability of A549 cells significantly increased following nicotine treatment compared with PBS-treated A549 cells $(\mathrm{P}<0.01)$. However, nicotine-treated cells transfected with GSTA1-siRNA exhibited significantly decreased invasive ability compared with nicotine-treated cells transfected with scramble siRNA ( $\mathrm{P}<0.01$; Fig. 4).

GSTA1 suppression inhibits the nicotine-induced adhesion abilities of A549 cells. Cell adhesion assays demonstrated that significantly increased adhesion activity was observed in nicotine-stimulated A549 cells compared with PBS-treated cells transfected with scramble siRNA $(\mathrm{P}<0.01)$. However, GSTA1-siRNA knockdown significantly inhibited the adhesion activity of nicotine treated $(\mathrm{P}<0.01)$ and untreated $(\mathrm{P}<0.05)$ A549 cells compared with scramble siRNA nicotine-treated and untreated cells, respectively (Fig. 5).

GSTA1 suppression inhibits nicotine-induced EMT of A549 cells. To investigate the effect of GSTA1 on EMT in A549 cells, the expression of the epithelial markers E-cadherin and keratin, and the mesenchymal markers vimentin and $\mathrm{N}$-cadherin, were determined by western blot analysis. As presented in Fig. 6, compared with untreated cells transfected with scramble siRNA, levels of E-cadherin and keratin were significantly downregulated $(\mathrm{P}<0.05)$, whereas levels of vimentin and $\mathrm{N}$-cadherin were significantly upregulated $(\mathrm{P}<0.01)$ in nicotine-treated cells transfected with scramble siRNA. Following GSTA1 
knockdown, levels of E-cadherin and keratin were significantly increased $(\mathrm{P}<0.05)$, whereas levels of vimentin and $\mathrm{N}$-cadherin were significantly reduced $(\mathrm{P}<0.05)$ compared with untreated cells transfected with scramble siRNA. In nicotine-treated A549 cells, levels of E-cadherin $(\mathrm{P}<0.05)$ and keratin $(\mathrm{P}<0.01)$ were significantly increased and levels of vimentin $(\mathrm{P}<0.05)$ and $\mathrm{N}$-cadherin $(\mathrm{P}<0.01)$ were significantly reduced compared with nicotine-treated cells transfected with scramble siRNA.

\section{Discussion}

Glutathione S-transferases are a multigene family of phase II isoenzymes that catalyze the conjugation of a variety of carcinogens, environmental toxins and endogenous compounds with glutathione (22). Polymorphisms associated with the altered expression of these genes may affect the metabolism of carcinogens and chemotherapeutic agents (23), resulting in an increased risk of various malignances (24-30). Previous studies have demonstrated that GSTA1 overexpression protects tumor cells from doxorubicin and reactive oxygen species-induced apoptosis (31-34). GSTA1 also serves a role in regulating the proliferation of Caco-2 cells (35). Recently, it has been demonstrated that GSTA1 promotes the proliferation of lung cancer cells (15). In the present study, it was demonstrated that the results from the MTT assay were consistent with those from a previous study (15). Furthermore, the present study demonstrated that GSTA1 suppression inhibited lung cancer cell invasion and adhesion, indicating that GSTA1 is associated with lung cancer metastasis.

Although there is insufficient evidence to classify nicotine as a carcinogen, nicotine has tumor-promoting properties. It has been demonstrated that nicotine promotes tumor growth and metastasis by inducing EMT, cell migration and invasion, angiogenesis, as well as suppressing apoptosis induced by drugs or radiation (36-38). In the present study, nicotine was used to treat A549 cells, and it was determined that the expression of GSTA1 was induced by nicotine. To determine whether GSTA1 was involved in mediating the effect of nicotine on lung cancer cells, GSTA1 was knocked down in A549 cells by siRNA. The results indicated that nicotine-induced lung cancer cell viability, invasion and adhesion were suppressed following GSTA1 knockdown.

It has been suggested that the EMT is the driving force of metastasis (7). During EMT, epithelial cells lose their apical and basolateral polarity, break cell-cell attachment and transform into mesenchymal cells (39). Notably, the EMT is reversible and the mesenchymal-epithelial transition is a reversion back towards the epithelial phenotype (40). E-cadherin and keratin are key markers of the epithelial phenotype and the loss of these proteins leads to the loss of cell junctions and the promotion of metastasis $(41,42)$. Vimentin and $\mathrm{N}$-cadherin are mesenchymal cell markers and have crucial roles in cellular migration $(43,44)$. In the present study, GSTA1 affected the expression of EMT markers of A549 lung cancer cells. In addition, the present findings indicated that the nicotine-induced EMT was reversed following GSTA1 knockdown. These results suggest that the effect of GSTA1 on EMT may explain its effect on lung cancer metastasis.

In conclusion, the present study demonstrated that GSTA1 promotes lung cancer cell invasion and adhesion. In addition, the present results suggest that nicotine increases the viability, invasion and adhesion abilities of A549 lung cancer cells and that this effect is mediated by GSTA1. GSTA1 exerts its effect on lung cancer cell metastasis by promoting the EMT. The present study suggests that GSTA1 serves a potential role GSTA1 in lung cancer metastasis and therefore may be a novel target for lung cancer treatment.

\section{References}

1. Torre LA, Siegel RL and Jemal A: Lung Cancer Statistics. Adv Exp Med Biol 893: 1-19, 2016.

2. Jemal A, Siegel R, Ward E, Hao Y, Xu J, Murray T and Thun MJ: Cancer statistics, 2008. CA Cancer J Clin 58: 71-96, 2008.

3. Nguyen DX, Bos PD and Massagué J: Metastasis: From dissemination to organ-specific colonization. Nat Rev Cancer 9: 274-284, 2009.

4. Steeg PS: Tumor metastasis: Mechanistic insights and clinical challenges. Nat Med 12: 895-904, 2006.

5. Chambers AF, Groom AC and MacDonald IC: Dissemination and growth of cancer cells in metastatic sites. Nat Rev Cancer 2: 563-572, 2002

6. Fidler IJ: The pathogenesis of cancer metastasis: The 'seed and soil' hypothesis revisited. Nat Rev Cancer 3: 453-458, 2003.

7. Thiery JP: Epithelial-mesenchymal transitions in tumour progression. Nat Rev Cancer 2: 442-454, 2002.

8. Brabletz T, Hlubek F, Spaderna S, Schmalhofer O, Hiendlmeyer E, Jung A and Kirchner T: Invasion and metastasis in colorectal cancer: Epithelial-mesenchymal transition, mesenchymal-epithelial transition, stem cells and beta-catenin. Cells Tissues Organs 179: 56-65, 2005.

9. Hayes JD, Flanagan JU and Jowsey IR: Glutathione transferases. Annu Rev Pharmacol Toxicol 45: 51-88, 2005.

10. Khan MS, Khan MK, Siddiqui MH and Arif JM: An in vivo and in silico approach to elucidate the tocotrienol-mediated fortification against infection and inflammation induced alterations in antioxidant defense system. Eur Rev Med Pharmacol Sci 15: 916-930, 2011.

11. Lee WH, Morton RA, Epstein JI, Brooks JD, Campbell PA, Bova GS, Hsieh WS, Isaacs WB and Nelson WG: Cytidine methylation of regulatory sequences near the pi-class glutathione S-transferase gene accompanies human prostatic carcinogenesis. Proc Natl Acad Sci USA 91: 11733-11737, 1994.

12. Niu D, Zhang J, Ren Y, Feng H and Chen WN: HBx genotype D represses GSTP1 expression and increases the oxidative level and apoptosis in HepG2 cells. Mol Oncol 3: 67-76, 2009.

13. Zhang YJ, Chen Y, Ahsan H, Lunn RM, Chen SY, Lee PH, Chen CJ and Santella RM: Silencing of glutathione S-transferase P1 by promoter hypermethylation and its relationship to environmental chemical carcinogens in hepatocellular carcinoma. Cancer Lett 221: 135-143, 2005.

14. Reszka E, Wasowicz W and Gromadzinska J: Genetic polymorphism of xenobiotic metabolising enzymes, diet and cancer susceptibility. Br J Nutr 96: 609-619, 2006.

15. Pan XD, Yang ZP, Tang QL, Peng T, Zhang ZB, Zhou SG, Wang GX, He B and Zang LQ: Expression and function of GSTA1 in lung cancer cells. Asian Pac J Cancer Prev 15: 8631-8635, 2014.

16. Hecht SS: Cigarette smoking: Cancer risks, carcinogens, and mechanisms. Langenbecks Arch Surg 391: 603-613, 2006.

17. Guingab-Cagmat J, Bauzo RM, Bruijnzeel AW, Wang KK, Gold MS and Kobeissy FH: Methods in tobacco abuse: Proteomic changes following second-hand smoke exposure. Methods Mol Biol 829: 329-348, 2012.

18. Davis R, Rizwani W, Banerjee S, Kovacs M, Haura E, Coppola D and Chellappan S: Nicotine promotes tumor growth and metastasis in mouse models of lung cancer. PLoS One 4: e7524, 2009.

19. Grozio A, Catassi A, Cavalieri Z, Paleari L, Cesario A and Russo P: Nicotine, lung and cancer. Anticancer Agents Med Chem 7: 461-466, 2007.

20. Cattaneo MG, Codignola A, Vicentini LM, Clementi F and Sher E: Nicotine stimulates a serotonergic autocrine loop in human small-cell lung carcinoma. Cancer Res 53: 5566-5568, 1993.

21. Livak KJ and Schmittgen TD: Analysis of relative gene expression data using real-time quantitative PCR and the 2(-Delta Delta C(T)) Method. Methods 25: 402-408, 2001. 
22. Vos RM and Van Bladeren PJ: Glutathione S-transferases in relation to their role in the biotransformation of xenobiotics. Chem Biol Interact 75: 241-265, 1990.

23. Watson MA, Stewart RK, Smith GB, Massey TE and Bell DA: Human glutathione S-transferase P1 polymorphisms: Relationship to lung tissue enzyme activity and population frequency distribution. Carcinogenesis 19: 275-280, 1998.

24. Stoehlmacher J, Park DJ, Zhang W, Groshen S, Tsao-Wei DD, $\mathrm{Yu} \mathrm{MC}$ and Lenz HJ: Association between glutathione S-transferase P1, T1, and M1 genetic polymorphism and survival of patients with metastatic colorectal cancer. J Natl Cancer Inst 94: 936-942, 2002.

25. Howells RE, Dhar KK, Hoban PR, Jones PW, Fryer AA, Redman CW and Strange RC: Association between glutathione-S-transferase GSTP1 genotypes, GSTP1 over-expression and outcome in epithelial ovarian cancer. Int $\mathrm{J}$ Gynecol Cancer 14: 242-250, 2004.

26. Wenzlaff AS, Cote ML, Bock CH, Land SJ and Schwartz AG GSTM1, GSTT1 and GSTP1 polymorphisms, environmental tobacco smoke exposure and risk of lung cancer among never smokers: A population-based study. Carcinogenesis 26: 395-401, 2005.

27. White DL, Li D, Nurgalieva Z and El-Serag HB: Genetic variants of glutathione $\mathrm{S}$-transferase as possible risk factors for hepatocellular carcinoma: A HuGE systematic review and meta-analysis. Am J Epidemiol 167: 377-389, 2008.

28. Kilburn L, Okcu MF, Wang T, Cao Y, Renfro-Spelman A, Aldape KD, Gilbert MR and Bondy M: Glutathione S-transferase polymorphisms are associated with survival in anaplastic glioma patients. Cancer 116: 2242-2249, 2010.

29. Sergentanis TN and Economopoulos KP: GSTT1 and GSTP1 polymorphisms and breast cancer risk: A meta-analysis. Breast Cancer Res Treat 121: 195-202, 2010.

30. Xu Z, Zhu H, Luk JM, Wu D, Gu D, Gong W, Tan Y, Zhou J, Tang J, Zhang Z, et al: Clinical significance of SOD2 and GSTP1 gene polymorphisms in Chinese patients with gastric cancer. Cancer 118: 5489-5496, 2012.

31. Sharma A, Patrick B, Li J, Sharma R, Jeyabal PV, Reddy PM, Awasthi S and Awasthi YC: Glutathione S-transferases as antioxidant enzymes: Small cell lung cancer (H69) cells transfected with hGSTA1 resist doxorubicin-induced apoptosis. Arch Biochem Biophys 452: 165-173, 2006.

32. Yang Y, Sharma R, Sharma A, Awasthi S and Awasthi YC: Lipid peroxidation and cell cycle signaling: 4-hydroxynonenal, a key molecule in stress mediated signaling. Acta Biochim Pol 50: 319-336, 2003.
33. Cheng JZ, Singhal SS, Sharma A, Saini M, Yang Y, Awasthi S, Zimniak P and Awasthi YC: Transfection of mGSTA4 in HL-60 cells protects against 4-hydroxynonenal-induced apoptosis by inhibiting JNK-mediated signaling. Arch Biochem Biophys 392: 197-207, 2001.

34. Zhao T, Singhal SS, Piper JT, Cheng J, Pandya U, Clark-Wronski J, Awasthi $S$ and Awasthi YC: The role of human glutathione S-transferases hGSTA1-1 and hGSTA2-2 in protection against oxidative stress. Arch Biochem Biophys 367: 216-224, 1999.

35. Adnan H, Quach H, MacIntosh K, Antenos M and Kirby GM: Low levels of GSTA1 expression are required for Caco-2 cell proliferation. PLoS One 7: e51739, 2012.

36. Egleton RD, Brown KC and Dasgupta P: Nicotinic acetylcholine receptors in cancer: Multiple roles in proliferation and inhibition of apoptosis. Trends Pharmacol Sci 29: 151-158, 2008.

37. Dasgupta P, Rizwani W,Pillai S, Kinkade R, Kovacs M, Rastogi S, Banerjee S, Carless M, Kim E, Coppola D, et al: Nicotine induces cell proliferation, invasion and epithelial-mesenchymal transition in a variety of human cancer cell lines. Int J Cancer 124: 36-45, 2009.

38. Heeschen C, Jang JJ, Weis M, Pathak A, Kaji S, Hu RS, Tsao PS, Johnson FL and Cooke JP: Nicotine stimulates angiogenesis and promotes tumor growth and atherosclerosis. Nat Med 7: 833-839, 2001.

39. Kalluri R and Weinberg RA: The basics of epithelial-mesenchymal transition. J Clin Invest 119: 1420-1428, 2009.

40. Lim J and Thiery JP: Epithelial-mesenchymal transitions: Insights from development. Development 139: 3471-3486, 2012.

41. Hay ED and Zuk A: Transformations between epithelium and mesenchyme: Normal, pathological, and experimentally induced. Am J Kidney Dis 26: 678-690, 1995.

42. Patel NA, Patel PS and Vora HH: Role of PRL-3, Snail, Cytokeratin and Vimentin expression in epithelial mesenchymal transition in breast carcinoma. Breast Dis 35: 113-127, 2015.

43. Zeisberg $M$ and Neilson EG: Biomarkers for epithelial-mesenchymal transitions. J Clin Invest 119: 1429-1437, 2009.

44. Kokkinos MI, Wafai R, Wong MK, Newgreen DF, Thompson EW and Waltham M: Vimentin and epithelial-mesenchymal transition in human breast cancer-observations in vitro and in vivo. Cells Tissues Organs 185: 191-203, 2007. 